\title{
Inhalational Isoflurane Sedation in Patients with Decompressive Craniectomy Suffering from Severe Subarachnoid Hemorrhage: A Case Series
}

\author{
Felix Lehmann¹ Marcus Müller ${ }^{2} \quad$ Julian Zimmermann² Ági Güresir ${ }^{3} \quad$ Victoria Lehmann ${ }^{1}$ \\ Christian Putensen ${ }^{1}$ Hartmut Vatter ${ }^{3}$ Erdem Güresir ${ }^{3}$
}

${ }^{1}$ Department of Anesthesiology and Intensive Care Medicine, Rheinische Friedrich-Wilhelms University of Bonn, Bonn, Germany

${ }^{2}$ Department of Neurology, Rheinische Friedrich-Wilhelms

University of Bonn, Bonn, Germany

${ }^{3}$ Department of Neurosurgery, Rheinische Friedrich-Wilhelms

University of Bonn, Bonn, Germany

J Neuroanaesthesiol Crit Care 2020;7:27-33

\begin{abstract}
Address for correspondence Felix Lehmann, MD, Department of Anaesthesiology and Intensive Care Medicine, Rheinische Friedrich-Wilhelms University of Bonn, Sigmund-Freud-Strasse 25,53127 Bonn, Germany (e-mail: felix.lehmann@ukbonn.de).
\end{abstract}

\section{Abstract}

Keywords

- decompressive craniectomy

- intracranial pressure

- sedation

- subarachnoid hemorrhage

- volatile anesthetics
Background Severe aneurysmal subarachnoid hemorrhage (SAH) may lead to the necessity of decompressive craniectomy (DC) to treat refractory elevated intracranial pressure (ICP). In some patients, adequate deep sedation, as one part of conservative treatment, cannot be achieved. Recent investigations suggest that inhalative sedation might not be as detrimental as considered before, and therefore a treatment option.

Materials and Methods A retrospective analysis of seven patients was performed who suffered from aneurysmal SAH (Hunt-Hess grade 3-5, Fisher's score 3 ) and underwent DC due to a critically elevated ICP. In these patients, the target sedation level could not be achieved even with high doses of intravenous sedatives. Thus, the sedative regimen was switched to inhaled anesthesia with isoflurane. Mean arterial pressure (MAP), ICP, cerebral perfusion pressure (CPP), levels of vasopressors, and respiratory parameters were analyzed.

Results Deep sedation (Richmond Agitation-Sedation Scale [RASS] -5, mean-fractional end-expiratory gas concentration [mean- $F_{\text {et }}$ ] $0.78 \%$ ) was rapidly achieved in all patients after commencing general anesthesia with isoflurane. ICP remained stable when comparing 1 hour before the onset of isoflurane sedation (1) with 6 (2), and 12 hours (3) after commencing isoflurane anesthesia (mean ICP [1] $13.83 \mathrm{~mm} \mathrm{Hg}$; [2] $12.57 \mathrm{~mm} \mathrm{Hg}$; [3] $11.14 \mathrm{~mm} \mathrm{Hg}$ ). The mean duration of application was 9 ( \pm 4 ) days. CPP could be maintained above $70 \mathrm{~mm} \mathrm{Hg}$ without the need for extended vasopressor usage.

Conclusion In a setting of severe SAH and critically elevated ICP with the need for aggressive multimodal therapy, isoflurane was safely applied in those patients. Our sedation goal was rapidly achieved and critical rise in ICP was not observed. Further investigations are required to demonstrate that inhaled anesthesia with isoflurane can be a promising alternative option, as this drug has better controllable pharmacokinetics, no clinically relevant accumulation of the drug itself, and potential neuroprotective effects (so far reported in different animal models).
DOI https://doi.org/ 10.1055/s-0039-1693525 ISSN 2348-0548.
Copyright (c2020 Indian Society of Neuroanaesthesiology and Critical Care
License terms

(1) (1) $\odot \circledast$ 


\section{Introduction}

Severe aneurysmal subarachnoid hemorrhage(SAH) may lead, primarily or during the treatment course, to the necessity of decompressive craniectomy (DC) to treat refractory elevated intracranial pressure (ICP). ${ }^{1}$ In some patients, an adequate deep sedation as one part of conservative treatment of elevated ICP cannot be achieved during the treatment course. ${ }^{2}$ Modern sedation concepts for patients in the intensive care unit (ICU) include combinations of different substances such as benzodiazepines, opioids, and propofol. ${ }^{3}$ In a neuro-ICU (NICU), there might be an additional need for barbiturates. In general, the main purpose of sedation in a critically ill patient is to keep the patient free of stressful and/or painful stimuli. Important additional goals in the NICU are reduction in the neuronal oxygen consumption $\left(\mathrm{CMRO}_{2}\right)$, reduction of an elevated ICP, and prevention or treatment of seizures. Limitations of the afore mentioned drugs might evolve due to accumulation or tolerance and ceiling effects. ${ }^{4}$

Traditionally, inhaled sedation is not used in the NICU, due to the potential risk of a rising ICP. This effect might be related to the vasodilating effects of volatile anesthetics. Among these substances, sevoflurane has the least vasodilating effects when compared with isoflurane, desflurane, and halothane. ${ }^{5-7}$ Scientific evidence is lacking especially regarding the long-term use of these substances for sedation in ICU as opposed to the short-term use in the operating theater.

Recently, two studies demonstrated that the use of volatile anesthetics might be a feasible option for sedation in the NICU. Villa et al ${ }^{8}$ showed an increased regional cerebral blood flow without a rise in the ICP when a sedative regime with isoflurane had been used. In addition, Bösel et $\mathrm{al}^{9}$ demonstrated that the use of inhaled isoflurane led to an effective sedation without relevant rises in ICP in a mixed population of NICU patients who suffered from intracerebral hematoma (ICH), SAH, or acute ischemic stroke (AIS). In their study, the use of isoflurane was restricted to patients without critically elevated ICPs ( $<18 \mathrm{~mm} \mathrm{Hg}$ ). In contrast, recent data by Purrucker et $\mathrm{al}^{10}$ suggested that the use of sevoflurane in patients with intracranial hemorrhage, ischemic stroke, intraventricular hemorrhage, and SAH showed an intolerable increase in ICP in about one-third of patients.
Considering the potential benefits of a sedative regimen using a drug that shows low metabolic rates (isoflurane $<0.2 \%$ ) combined with the possibility of therapeutic drug monitoring 10 to 20 times a minute leads to a high interest in using this sedative in the setting of an NICU.

However, the use of inhaled sedatives in patients with elevated ICP is rare, and data on the effect of inhaled sedatives in patients with high-grade SAH are missing. Therefore, we analyzed SAH patients who were treated with volatile anesthetics due to the inability to reach the target sedation level of Richmond Agitation-Sedation Scale (RASS) - 5 who underwent DC during the treatment of SAH.

\section{Materials and Methods}

Ethical approval was obtained by the ethics committee of the University of Bonn. Written informed consent was waived, as we retrospectively analyzed data that have been routinely acquired.

We analyzed seven patients with severe SAH (Hunt-Hess grade 3-5, Fisher's score 3 ) with an elevated ICP (> $15 \mathrm{~mm}$ $\mathrm{Hg}$ ) who underwent DC due to refractory elevated ICP following severe brain edema ( $>25 \mathrm{~mm} \mathrm{Hg}$ for at least $5 \mathrm{~min}$ utes, not responding to standard treatment). During DC, a large (at least $11 \times 16 \mathrm{~cm}$ ), fronto-temporo-parietal bone flap extending from the supraorbital rim behind the lambdoid suture and from the temporal base close to the midline was removed at the site of the main pathology. Dura was opened widely in a stellate fashion. Patients were treated according to the international guidelines for SAH. ${ }^{11-13}$ Standard treatment consisted of deep sedation (RASS -5) with propofol or midazolam in combination with sufentanil, osmotic therapy (mannitol) and antiacidotic therapy (THAM), hyperventilation, and cerebrospinal fluid drainage by an external ventricular drain (EVD).

Detailed patient data are listed in - Table 1 .

All patients received an arterial line for invasive blood pressure measurement and arterial blood gas analysis. Blood pressure and heart rate were continuously recorded. Vasopressors (norepinephrine or vasopressin) were administered to achieve an adequate mean arterial pressure (MAP) of at least $80 \mathrm{~mm} \mathrm{Hg}$, if cerebral perfusion pressure (CPP)

Table 1 Patients' characteristics

\begin{tabular}{|l|l|l|l|l|l|l|l|}
\hline $\begin{array}{l}\text { Patient } \\
\text { number }\end{array}$ & $\begin{array}{l}\text { Hunt-Hess } \\
\text { grade }\end{array}$ & $\begin{array}{l}\text { Fisher's } \\
\text { score }\end{array}$ & $\begin{array}{l}\text { Aneurysm } \\
\text { (localization) }\end{array}$ & Treatment & $\begin{array}{l}\text { Volatile } \\
\text { sedation (days) }\end{array}$ & $\begin{array}{l}\text { Discharge } \\
\text { from ICU }\end{array}$ & MRS at 6 months \\
\hline 1 & 5 & 3 & ICA, left & Coil & 5 & No (death) & 6 \\
\hline 2 & 4 & 3 & A com & Coil & 3 & Yes & 5 \\
\hline 3 & 3 & 3 & P com & Coil & 11 & Yes & 6 \\
\hline 4 & 3 & 3 & A com & Coil & 13 & Yes & 5 \\
\hline 5 & 4 & 3 & P com & Coil & 6 & Yes & 4 \\
\hline 6 & 4 & 3 & A com & Coil & 12 & Yes & 4 \\
\hline 7 & 5 & 3 & ICA, left & Clip & 14 & No (death) & 6 \\
\hline
\end{tabular}

Abbreviations: Acom, anterior communicating artery ; ICA, internal carotid artery; ICU, intensive care unit; MRS, modified Rankin-scale; Pcom, arteria communicans posterior. 
was $<70 \mathrm{~mm} \mathrm{Hg}$. In case of imminent left ventricular heart failure, as obtained by either transesophageal echocardiography or transpulmonary dilution technique (PICCO; Pulsion, Germany), hemodynamic therapy was expanded with inotropes (dobutamine, milrinone) as required.

All patients were ventilated with a positive end-expiratory pressure (PEEP) of at least 10 mbar, according to our institutional standards. Pressure amplitude was set to reach a lung-protective tidal volume of $6 \mathrm{~mL} / \mathrm{kg}$ of predicted bodyweight or higher in case of ICP-relevant $\mathrm{CO}_{2}$ retention.

ICP was either measured by EVD or via intraparenchymal probe (Spiegelberg; Hamburg, Germany). All patients were screened for cerebral vasospasm (CVS) on a daily base by transcranial Doppler sonography. In case of increasing mean flow velocity (MFV) of the middle cerebral artery (MCA), a cerebral computed tomography (CT) scan with CT angiography and CT perfusion was performed.

If ICP peaks still existed ( $>20 \mathrm{~mm} \mathrm{Hg}$ for $>5$ minutes) following DC, patients were sedated. Sedation management followed local protocols first treating with propofol (starting from $2 \mathrm{mg} / \mathrm{kgBW} / \mathrm{h}$ ) or midazolam (starting from $0.1 \mathrm{mg} / \mathrm{kgBW} / \mathrm{h}$ ) in combination with sufentanil $(0.1-0.5 \mu \mathrm{g} / \mathrm{kgBW} / \mathrm{h})$. If ICP peaks persisted, sedation was increased aiming at an RASS level of -5 . RASS was first described and validated by Sessler et $\mathrm{al}^{14,15}$ and is considered to be the gold standard in monitoring the level of sedation in intensive care patients. ${ }^{16}$ In case of the inability to reach the target RASS level, inhaled isoflurane was started with the AnaConDa (Sedana Medical; Uppsala, Sweden). Fractional end-expiratory gas concentration $\left(\mathrm{F}_{\mathrm{et}}\right)$ was measured with an anesthetic gas monitor (Vamos; Dräger, Germany) targeting at the desired level of RASS -5 . The technical details of inhaled sedation using the AnaConDa are described elsewhere. ${ }^{17}$ Other intravenous sedatives were discontinued after the initiation of the AnaConDa.
If ICP remained stable ( $<20 \mathrm{~mm} \mathrm{Hg}$ ), the sedation was gradually reduced aiming at an RASS level of 0 .

All data were collected in an Excel (Microsoft; Redmond, Washington, United States). Mean values and standard deviation were directly calculated in Excel. Graphics were created using Prism 6 software (GraphPad Software; San Diego, California, United States). Statistical analyses were performed in SPSS (IBM; Armonk, New York, United States) when appropriate.

\section{Results}

A deep sedation (mean- $\mathrm{F}_{\mathrm{et}} 0.78 \%$ ) was achieved in all patients within seconds commencing with inhaled isoflurane. ICP remained stable comparing the values 1 hour before onset of isoflurane sedation with 6 hours and 12 hours after starting the volatile anesthetic (mean ICP $13.14 \mathrm{~mm} \mathrm{Hg}$ [onset]; $12.57 \mathrm{~mm} \mathrm{Hg}$ [6 hours]; $11.14 \mathrm{~mm} \mathrm{Hg}$ [12 hours]) (-Fig. 1).

The mean duration of application was $9( \pm 4)$ days without loss of the sedation effect. Dosage ranged from $\mathrm{F}_{\mathrm{et}} 0.7 \%$ up to $\mathrm{F}_{\text {et }}$ $1.4 \%$ to reach the target sedation goal of RASS -5 . Anesthesia was delivered in a balanced fashion together with sufentanil. Intravenous doses of sufentanil ranged from 30 to $46 \mu \mathrm{g} / \mathrm{h}$.

CPP was maintained above $70 \mathrm{~mm} \mathrm{Hg}$. We could even observe a slight ICP reduction from 13.1 to $11.1 \mathrm{~mm} \mathrm{Hg}$. Consecutively, CPP increased from 73.04 to $79.8 \mathrm{~mm} \mathrm{Hg}$, as MAP was kept stable, ranging from 83 to $99 \mathrm{~mm} \mathrm{Hg}$; hence, differences were not statistically significant.

Heart rate remained stable throughout the entire period of gas administration. Electrocardiographic (ECG) abnormalities were not recorded.

There was no need for an extended vasopressor usage. The norepinephrine dose increased from a mean of 24 to $32 \mu \mathrm{g} / \mathrm{min}$ within 12 hours; hence, differences were not

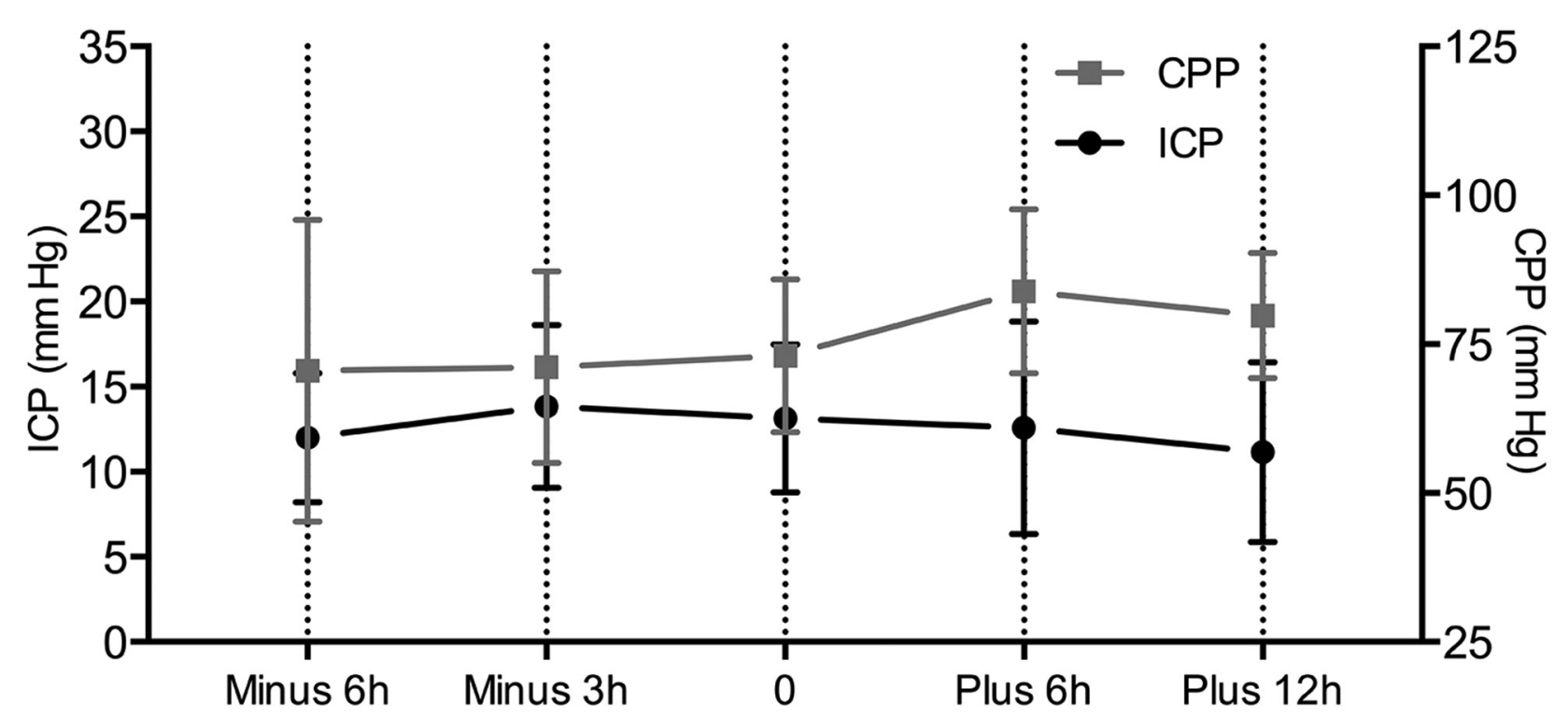

Fig. 1 Cerebral perfusion pressure (CPP) and intracranial pressure (ICP) at the time of initiation of inhalational sedation (0), as well as 1 and 6 hours before, and 6 and 12 hours after onset (mean values \pm standard deviation). 
statistically significant. The additional use of vasopressin was necessary in one patient. This has been linked to a vasoplegia during the septic shock of the patient rather than the onset of volatile sedation (-Fig. 2).

Gas exchange remained unchanged. Fraction of inspired oxygen $\left(\mathrm{F}_{\mathrm{i}} \mathrm{O}_{2}\right)$ was kept stable between 50 and $60 \%$ resulting in peripheral oxygen saturation $\left(\mathrm{SpO}_{2}\right)$ of 97 to $100 \%$. Arterial carbon dioxide tension $\left(\mathrm{PaCO}_{2}\right)$ levels were kept stable, and ventilator settings remained unchanged. Interpretation of arterial oxygen tension $\left(\mathrm{PaO}_{2}\right)$ changes was limited, due to the small sample size.

All our NICU patients were monitored for pulmonary, renal, hepatic, and gastrointestinal malfunction. We did not observe any adverse events related to the administration of inhaled isoflurane (-Table 2 ).

\section{Discussion}

In this series of seven patients, we were able to show that inhaled sedation with isoflurane is a promising alternative in the event of insufficient intravenous sedation. Isoflurane inhalation did not increase the ICP and showed a trend toward a slight decrease in isoflurane-sedated SAH patients.

Refractory elevated ICP following SAH may require a DC. ${ }^{1,18}$ In an NICU setting, the possibility of a deep sedation for a longer period of time is essential for these patients. Such a

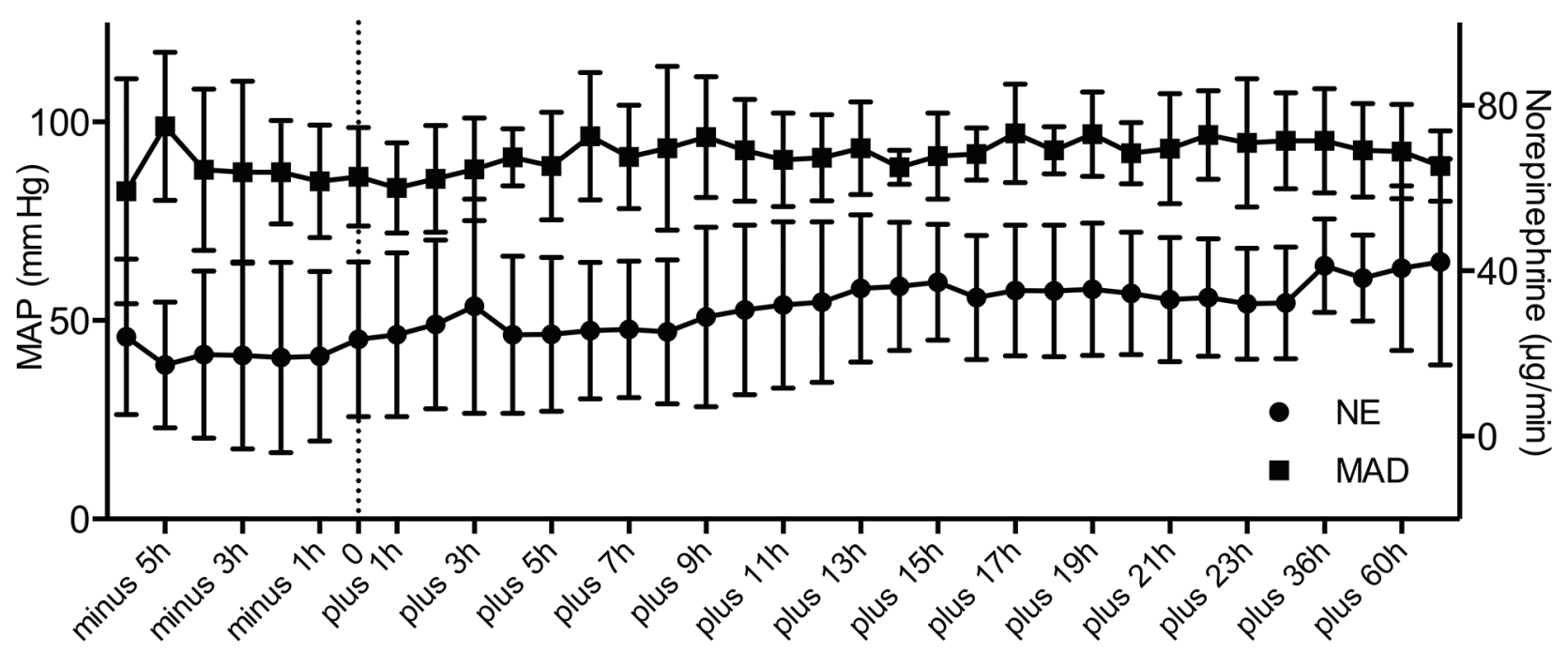

Fig. 2 Middle arterial pressure (MAP) and the norepinephrine (NE) doses before and after the onset of inhalational sedation. Mean values \pm standard deviation.

Table 2 Short-term changes of selected parameters 6 hours before and after switch to volatile sedation

\begin{tabular}{|l|l|l|l|l|l|}
\hline Parameters & $\begin{array}{l}-6 \mathrm{~h} \\
\text { Mean (SD) }\end{array}$ & $\begin{array}{l}-1 \mathrm{~h} \\
\text { Mean (SD) }\end{array}$ & $\begin{array}{l}\text { Baseline } \\
\text { Mean (SD) }\end{array}$ & $\begin{array}{l}\text { +6 h } \\
\text { Mean (SD) }\end{array}$ & $\begin{array}{l}\text { Mean (SD) } \\
\text { Mea }\end{array}$ \\
\hline $\mathrm{MAP}(\mathrm{mm} \mathrm{Hg})$ & $82.56(28.36)$ & $85(14.26)$ & $86.19(12.39)$ & $96.43(16.06)$ & $90.95(10.84)$ \\
\hline $\mathrm{HR}($ beats/min) & $84.17(19.60)$ & $75.83(11.14)$ & $81.43(14.64)$ & $91.43(16.00)$ & $85.43(12.43)$ \\
\hline $\mathrm{ICP}(\mathrm{mm} \mathrm{Hg})$ & $12(3.79)$ & $13.83(4.79)$ & $13.14(4.34)$ & $12.57(6.24)$ & $11.14(5.30)$ \\
\hline $\mathrm{CPP}(\mathrm{mm} \mathrm{Hg})$ & $70.56(25.36)$ & $71.17(16.13)$ & $73.05(12.86)$ & $83.86(13.80)$ & $79.81(10.51)$ \\
\hline $\mathrm{F}_{\text {et }}($ vol\%) & - & - & $0.78(0.36)$ & $0.81(0.25)$ & $0.89(0.36)$ \\
\hline Norepinephrine $(\mu \mathrm{g} / \mathrm{min})$ & $24(18.83)$ & $19.33(20.53)$ & $23.42(18.72)$ & $25.57(16.56)$ & $32.43(19.41)$ \\
\hline Vasopressin $(\mathrm{IE} / \mathrm{h})$ & - & - & 0 & $1\left({ }^{*}\right)$ & $1\left(^{*}\right)$ \\
\hline $\mathrm{F}_{\mathrm{i}} \mathrm{O}_{2}(\%)$ & $50.83(15.63)$ & $50.83(12.81)$ & $52.86(20.38)$ & $51.43(16.00)$ & $46.67(14.72)$ \\
\hline $\mathrm{PEEP}(\mathrm{mbar})$ & $10(1.41)$ & $10.33(1.51)$ & $10.57(1.51)$ & $11.43(1.81)$ & $12(2.10)$ \\
\hline $\mathrm{PaO}_{2}(\mathrm{~mm} \mathrm{Hg})$ & $99.40(29.08)$ & $112\left(^{*}\right)$ & $116(94.05)$ & $123(39.15)$ & $103(16.26)$ \\
\hline $\mathrm{PaCO}_{2}(\mathrm{~mm} \mathrm{Hg})$ & $36.15(8.42)$ & $50\left(^{*}\right)$ & $46(18.38)$ & $46(16.70)$ & $53\left(^{*}\right)$ \\
\hline $\mathrm{SpO}_{2}(\%)$ & $97.67(2.42)$ & $98.33(1.37)$ & $98.57(1.90)$ & $98.67(1.63)$ & $99(1.67)$ \\
\hline
\end{tabular}

Abbreviations: CPP, cerebral perfusion pressure; $F_{e t}$, fractional end-expiratory gas concentration; $\mathrm{F}_{\mathrm{i}} \mathrm{O}_{2}$, fraction of inspired oxygen; HR, heart rate; ICP, intracranial pressure; MAP, mean arterial pressure; $\mathrm{PaCO}_{2}$, arterial carbon dioxide tension; $\mathrm{PaO}_{2}$, arterial oxygen tension; PEEP, positive end-expiratory pressure; $\mathrm{SD}$, standard deviation; $\mathrm{SpO}_{2}$, peripheral oxygen saturation.

Means and SDs.

*Due to an incomplete dataset, a calculation of SD was impossible. Mean values were tested for significant differences using an unpaired student's $t$-test. 
sedation regimen aims at neuroprotection by decreasing the ICP and $\mathrm{CMRO}_{2}$ as there are no further surgical treatment options following DC.

The standard sedation regimen in patients suffering from severe SAH and elevated ICP is a two- or threefold combination of different substances, all of them being administered intravenously. Though opioids are regularly part of the sedation regimen, in our NICU, the second drug can either be a hypnotic agent such as propofol or a benzodiazepine (midazolam). In the event of a refractory ICP crisis and when the conservative and surgical therapies have been extended to a maximum including DC, we will use all three substances in combination or switch to inhaled sedation with isoflurane.

Up to date, it is unclear which combination is the best to use, ${ }^{19-21}$ but there is clear evidence that the site of action of all intravenous sedative agents is mainly the $\gamma$-aminobutyric acid (GABA) receptor. Limitations may occur during the course of a multifold combination of these drugs, such as tolerance, tachyphylaxis, and ceiling effects. ${ }^{4}$ In addition, specific side effects of different drugs such as the propofol infusion syndrome (PRIS) 22 have to be taken into account.

Other authors demonstrated a link between sedation and an emerging rate of delirium in ICU patients, ${ }^{23}$ which is responsible for an increase in ICU mortality ${ }^{24}$ and decreased long-term cognitive function. ${ }^{25}$ Especially GABAergic and anticholinergic substances seem to have a greater risk of triggering a delirium. Brain damage can evolve due to a direct damage as well as an iatrogenic damage following extended sedation.

Traditionally, there is some hesitation regarding the use of inhaled sedatives in patients with elevated ICP because volatile anesthetics may elevate the ICP due to vasodilatation of cerebral blood vessels. This effect has been shown in studies that have been performed in patients undergoing surgery in the operating theater and a rather short period of time. ${ }^{26-28}$ Relaxation of pulmonary arterial capillaries by isoflurane may ameliorate the Euler-Liljestrand mechanism (hypoxic pulmonary vasoconstriction) with an increase in the transpulmonary shunt fraction $(\mathrm{Qs} / \mathrm{Qt})$. Consequently, a rise in the $\mathrm{PaCO}_{2}$ would be observed. However, we could not observe such a rise in $\mathrm{PaCO}_{2}$ and subsequently an increase in the ICP during the course of isoflurane administration.

Due to the availability of the AnaConDa, it became feasible to use isoflurane in an ICU setting. Modern volatile anesthetics combine certain advantages as they are potent hypnotics that demonstrated an excellent controllability while the compound itself is not metabolized in the host. Isoflurane has favorable pharmacokinetics as only $0.2 \%$ of it undergoes metabolism. Pulmonary elimination is the main pathway. Together with a breath-by-breath measurement of end-expiratory gas concentration, isoflurane sedation gives the ICU physician the opportunity of pharmacologic drug monitoring several times per minute. Withdrawal of isoflurane leads to a measurable complete washout of the drug within minutes, which is very beneficial in case of NICU patients as short awakening times allow a quick and safe neurological assessment. ${ }^{17}$ Volatile anesthetics produce a good quality of sedation without adverse side effects. ${ }^{17}$

Furthermore, there is evidence for organo-protective effects of volatile anesthetics, which are linked to their ability to induce protection in terms of pre- and post-conditioning as it is seen in ischemia. ${ }^{29}$ Underlying mechanisms are manifold, reducing apoptosis by activation of mitogen-activated protein kinase (MAPK) pathways or reducing excitotoxicity via activation of GABA and/or $\mathrm{N}$-methyl-d-aspartate (NMDA) receptors. ${ }^{30}$ This effect could be demonstrated in the heart, ${ }^{31}$ the kidneys, ${ }^{32}$ and the brain. ${ }^{33,34}$ Currently, large multicenter trials are missing that elucidate the effect on mortality of ICU patients..$^{35}$

Brain inflammation following SAH might be one promoter of early brain damage (EBD) and therefore one cause for poor outcome of patients suffering from SAH, even if they receive the best known treatment of CVS, including reversal of CVS in a rat model. ${ }^{36,37}$ There is experimental evidence that isoflurane is capable of influencing EBD by direct immunological interaction via activation of a sphingosine-related pathway. ${ }^{38}$ In addition, it has been demonstrated that isoflurane can suppress post-SAH blood-brain barrier disruption. ${ }^{39}$ Thus, isoflurane is a promising substance in the NICU in terms of sedation because of its potential neuroprotective properties.

There are several limitations of this study. First, this is a retrospective observational study, and a small number of patients has been included. On the other hand, the cohort of patients is much more homogeneous (enrolled patients suffered from SAH and underwent DC) when compared with the two other studies using isoflurane in the NICU.,9 Due to the individual therapeutic decision in the course of unsuccessful intravenous sedation, isoflurane was administered at different times from the onset of SAH. Taking this into account, there might be an influence on pre- and post-conditioning, as well as direct immunomodulatory properties of the volatile anesthetic, one cannot extract other information than the feasibility of volatile anesthesia in the setting of the NICU. There was no control group and therefore no distinct statistical analysis other than the comparison of mean values.

Although we did not observe a pathological rise in ICP during the use of isoflurane, its use should only be considered in a setting of optimal neuromonitoring, at least the measurement of ICP, and it should be performed in a highly specialized unit, familiar with the examination and treatment of this patient population.

\section{Conclusion}

In a setting of severe SAH and critically elevated ICP with the need for aggressive multimodal therapy, isoflurane inhalation was safely applied. Our sedation goal was easily achieved, and undesirable effects such as a critical rise in ICP were not observed. Controlled clinical trials are warranted to evaluate the validity of these results, and the therapeutic value of sedation with isoflurane in patients with severe $\mathrm{SAH}$ and critically elevated ICP. 


\section{Conflict of Interest}

Dr. Lehmann reports personal fees from Sedana Medical, during the conduct of this study.

\section{References}

1 Güresir E, Raabe A, Setzer M, et al. Decompressive hemicraniectomy in subarachnoid haemorrhage: the influence of infarction, haemorrhage and brain swelling. J Neurol Neurosurg Psychiatry 2009;80(7):799-801

2 Rangel-Castilla L, Gopinath S, Robertson CS. Management of intracranial hypertension. Neurol Clin 2008;26(2):521-541

3 Martin J, Heymann A, Bäsell K, et al. Evidence and consensus-based German guidelines for the management of analgesia, sedation and delirium in intensive care-short version. Ger Med Sci 2010;8:Doc02

4 Shafer A. Complications of sedation with midazolam in the intensive care unit and a comparison with other sedative regimens. Crit Care Med 1998;26(5):947-956

5 Holmström A, Akeson J. Desflurane increases intracranial pressure more and sevoflurane less than isoflurane in pigs subjected to intracranial hypertension. J Neurosurg Anesthesiol 2004;16(2):136-143

6 Holmström A, Akeson J. Sevoflurane induces less cerebral vasodilation than isoflurane at the same A-line autoregressive index level. Acta Anaesthesiol Scand 2005;49(1):16-22

7 Bazin JE. Effects des agents anesthésiques sur la pression intracrânienne. Ann Fr Anesth Reanim 1997;16(4):445-452

8 Villa F, Iacca C, Molinari AF, et al. Inhalation versus endovenous sedation in subarachnoid hemorrhage patients: effects on regional cerebral blood flow. Crit Care Med 2012;40(10):2797-2804

9 Bösel J, Purrucker JC, Nowak F, et al. Volatile isoflurane sedation in cerebrovascular intensive care patients using AnaConDa $\left({ }^{\circledR}\right)$ : effects on cerebral oxygenation, circulation, and pressure. Intensive Care Med 2012;38(12):1955-1964

10 Purrucker JC, Renzland J, Uhlmann L, et al. Volatile sedation with sevoflurane in intensive care patients with acute stroke or subarachnoid haemorrhage using AnaConDa ${ }^{\circledR}$ : an observational study. Br J Anaesth 2015;114(6):934-943

11 Diringer MN, Bleck TP, Claude Hemphill J III, et al.; Neurocritical Care Society, Critical care management of patients following aneurysmal subarachnoid hemorrhage: recommendations from the Neurocritical Care Society's Multidisciplinary Consensus Conference. Neurocrit Care 2011;15(2):211-240

12 Connolly ES Jr, Rabinstein AA, Carhuapoma JR, et al; American Heart Association Stroke Council, Council on Cardiovascular Radiology and Intervention; Council on Cardiovascular Nursing; Council on Cardiovascular Surgery and Anesthesia; Council on Clinical Cardiology. Guidelines for the management of aneurysmal subarachnoid hemorrhage: a guideline for healthcare professionals from the American Heart Association/ American Stroke Association. Stroke 2012;43(6):1711-1737

13 Komotar RJ, Schmidt JM, Starke RM, et al. Resuscitation and critical care of poor-grade subarachnoid hemorrhage. Neurosurgery 2009;64(3):397-410, discussion 410-411

14 Sessler CN, Grap MJ, Brophy GM. Multidisciplinary management of sedation and analgesia in critical care. Semin Respir Crit Care Med 2001;22(2):211-226

15 Sessler CN, Gosnell MS, Grap MJ, et al. The Richmond Agitation-Sedation Scale: validity and reliability in adult intensive care unit patients. Am J Respir Crit Care Med 2002;166(10):1338-1344

16 Baron R, Binder A, Biniek R, et al; DAS-Taskforce 2015. Evidence and consensus based guideline for the management of delirium, analgesia, and sedation in intensive care medicine.
Revision 2015 (DAS-Guideline 2015)-short version. Ger Med Sci 2015;13:Doc19

17 Soukup J, Schärff K, Kubosch K, Pohl C, Bomplitz M, Kompardt J. State of the art: sedation concepts with volatile anesthetics in critically Ill patients. J Crit Care 2009;24(4):535-544

18 Dorfer C, Frick A, Knosp E, Gruber A. Decompressive hemicraniectomy after aneurysmal subarachnoid hemorrhage. World Neurosurg 2010;74(4-5):465-471

19 Teitelbaum JS, Ayoub O, Skrobik Y. A critical appraisal of sedation, analgesia and delirium in neurocritical care. Can. J Neurol Sci 2011;38(6):815-825

20 Bösel J, Dziewas R. Sedation and weaning in neurocritical care: can concepts from general critical care be applied? [article in German] Nervenarzt 2012;83(12):1533-1541

21 Roberts DJ, Hall RI, Kramer AH, Robertson HL, Gallagher CN, Zygun DA. Sedation for critically ill adults with severe traumatic brain injury: a systematic review of randomized controlled trials. Crit Care Med 2011;39(12):2743-2751

22 Roberts RJ, Barletta JF, Fong JJ, et al. Incidence of propofol-related infusion syndrome in critically ill adults: a prospective, multicenter study. Crit Care 2009;13(5):R169

23 Reade MC, Finfer S. Sedation and delirium in the intensive care unit. N Engl J Med 2014;370(5):444-454

24 Pisani MA, Kong SY, Kasl SV, Murphy TE, Araujo KL, Van Ness $\mathrm{PH}$. Days of delirium are associated with 1-year mortality in an older intensive care unit population. Am J Respir Crit Care Med 2009;180(11):1092-1097

25 van den Boogaard M, Schoonhoven L, Evers AW, van der Hoeven JG, van Achterberg T, Pickkers P. Delirium in critically ill patients: impact on long-term health-related quality of life and cognitive functioning. Crit Care Med 2012;40(1):112-118

26 Chui J, Mariappan R, Mehta J, Manninen P, Venkatraghavan L. Comparison of propofol and volatile agents for maintenance of anesthesia during elective craniotomy procedures: systematic review and meta-analysis. Can J Anaesth 2014;61(4):347-356

27 Hans P, Bonhomme V. Why we still use intravenous drugs as the basic regimen for neurosurgical anaesthesia. Curr Opin Anaesthesiol 2006;19(5):498-503

28 Massei R, Calappi E, Parma A, Granata G. Effects of inhalation anesthetics on intracranial pressure and cerebral blood flow velocity [article in Italian]. Minerva Anestesiol 1994;60(11):643-647

29 Kitano H, Kirsch JR, Hurn PD, Murphy SJ. Inhalational anesthetics as neuroprotectants or chemical preconditioning agents in ischemic brain. J Cereb Blood Flow Metab 2007;27(6):1108-1128

30 Deng J, Lei C, Chen Y, et al. Neuroprotective gases-fantasy or reality for clinical use? Prog Neurobiol 2014;115:210-245

31 Pagel PS. Myocardial protection by volatile anesthetics in patients undergoing cardiac surgery: a critical review of the laboratory and clinical evidence. J Cardiothorac Vasc Anesth 2013;27(5):972-982

32 Lee HT, Ota-Setlik A, Fu Y, Nasr SH, Emala CW. Differential protective effects of volatile anesthetics against renal ischemia-reperfusion injury in vivo. Anesthesiology 2004;101(6):1313-1324

33 Fukuda S, Warner DS. Cerebral protection. Br J Anaesth 2007;99(1):10-17

34 Plachinta RV, Hayes JK, Cerilli LA, Rich GF, Rich GF. Isoflurane pretreatment inhibits lipopolysaccharide-induced inflammation in rats. Anesthesiology 2003;98(1):89-95

35 Kunst G. From coronary steal to myocardial, renal, and cerebral protection: more questions than answers in anaesthetic preconditioning? Br J Anaesth 2014;112(6):958-960

36 Fujii M, Yan J, Rolland WB, Soejima Y, Caner B, Zhang JH. Early brain injury, an evolving frontier in subarachnoid hemorrhage research. Transl Stroke Res 2013;4(4):432-446 
37 Kooijman E, Nijboer CH, van Velthoven CTJ, et al. Long-term functional consequences and ongoing cerebral inflammation after subarachnoid hemorrhage in the rat. PLoS One 2014;9(6):e9058

38 Altay O, Suzuki H, Hasegawa Y, Ostrowski RP, Tang J, Zhang $\mathrm{JH}$. Isoflurane on brain inflammation. Neurobiol Dis 2014;62:365-371
39 Altay O, Suzuki H, Hasegawa Y, et al. Isoflurane attenuates blood-brain barrier disruption in ipsilateral hemisphere after subarachnoid hemorrhage in mice. Stroke 2012;43(9):2513-2516 